\title{
Changes in arterial blood pressure in hypertensive rats caused by long-term intake of milk fermented by Enterococcus faecalis CECT 5728
}

\author{
M. Miguel ${ }^{1}$, B. Muguerza ${ }^{2}$, E. Sánchez ${ }^{2}$, M. A. Delgado ${ }^{2}$, I. Recio ${ }^{1}$, M. Ramos ${ }^{1}$ and M. A. Aleixandre ${ }^{3 *}$ \\ ${ }^{1}$ Instituto de Fermentaciones Industriales (CSIC), Madrid, Spain \\ ${ }^{2}$ Grupo Leche Pascual, Aranda de Duero, Burgos, Spain \\ ${ }^{3}$ Instituto de Farmacología y Toxicología (CSIC), Facultad de Medicina, Universidad Complutense, 28040 Madrid, Spain
}

(Received 10 September 2004 - Revised 2 February 2005 - Accepted 7 February 2005)

\begin{abstract}
We have evaluated the changes in arterial blood pressure caused in spontaneously hypertensive rats (SHR) by long-term intake of an Enterococcus faecalis CECT 5728-fermented milk with significant angiotensin-converting enzyme (ACE)-inhibitory activity. After being weaned, male 3-week-old SHR were randomized into five groups. Until the 20th week of life, rats in each group were given one of the following drinking fluids: tap water (negative control 1), a fermented milk without ACE-inhibitory activity (negative control 2), captopril (100 mg/kg) (positive control), the E. faecalis CECT 5728 -fermented milk that had significant ACE-inhibitory activity, or Ca-enriched E. faecalis CECT 5728 -fermented milk. Animals in the different groups were then given tap water as drinking fluid from the 20th to 25th week of life. Systolic blood pressure (SBP) and diastolic blood pressure (DBP) were measured weekly in the rats, from the 6th to 25th week of life, by the tail-cuff method. A definite decrease in SBP and DBP could be observed in the rats treated with captopril and also in the rats that received the E. faecalis CECT 5728-fermented milks. The greatest antihypertensive effect was observed when the pharmacological treatment was administered. The effect of the Ca-enriched fermented milk was slightly more accentuated and more constant than the effect of the E. faecalis CECT 5728-fermented milk that had not been enriched in Ca. SBP and DBP increased in the treated SHR when the corresponding antihypertensive treatment was removed. Fermentation of milk with E. faecalis CECT 5728 may therefore be a successful strategy to produce a functional food with antihypertensive activity.
\end{abstract}

Blood pressure: Angiotensin-converting enzyme inhibition: Milk fermentation: Enterococcus faecalis

Hypertension is a common and usually progressive disorder, which, if not effectively treated, has a high mortality rate. The preferred antihypertensive treatments have changed progressively as better drugs have become available, and angiotensin-converting enzyme (ACE) inhibitors are widely used nowadays in the control of this disease. Through fermentation, a variety of small bioactive peptides that have ACE-inhibitory activity can be derived from milk protein hydrolysis. Some of these peptides have also been found to have antihypertensive properties in animals and human subjects. In this context, Nakamura et al. (1995a) reported the antihypertensive activity in spontaneously hypertensive rats (SHR) of both a fermented milk prepared from skimmed milk with a starter culture containing Lactobacillus helveticus and Saccharomyces cerevisiae, and two biologically active peptides isolated from it (Val-Pro-Pro:VPP) and (Ile-Pro-Pro:IPP). This sour milk also reduced systolic blood pressure (SBP) and diastolic blood pressure (DBP) in hypertensive patients (Hata et al. 1996). Later, Sipola et al. (2001, 2002) demonstrated that long-term oral intake of IPP and VPP, or a sour milk product fermented by L. helveticus LBK-16H containing these tripeptides, attenuated the development of hypertension in young pre-hypertensive SHR. Moreover,
L. helveticus LBK-16H-fermented milk containing bioactive tripeptides IPP and VPP in normal daily use had a blood pressure-lowering effect in hypertensive patients (Seppo et al. 2002, 2003).

Our research group has just demonstrated that four strains of Enterococcus faecalis, CECT 5727, CECT 5728, CECT 5826 and CECT 5827, are especially significant as producers of ACE-inhibitory peptides other than IPP and VPP. We have also demonstrated that the fermented milks produced using these selected $E$. faecalis strains possess acute antihypertensive effect in SHR after a single oral administration. Nevertheless, they did not modify the arterial blood pressure of the Wistar-Kyoto rats that were used as normotensive controls of the SHR (Muguerza et al. 2005).

The administration of $\mathrm{Ca}$ is paradoxically associated with a decrease in arterial blood pressure, and different studies carried out by our research group have also demonstrated that Caenriched diets can control hypertension in rats (López-Miranda et al. 1998; Civantos et al. 1999; Civantos Calzada \& Aleixandre de Artiñano, 2003; Civantos \& Aleixandre, 2004). Dietary Ca supplements also have beneficial effects in hypertensive patients (for reviews see Aleixandre \& Puerro, 1993; Aleixandre et al. 1993; Pryer et al. 1995; Allender et al. 1996; Resnick, 1999). 
The aim of the present study was to evaluate the blood pressurelowering effect caused in SHR by long-term intake of both an E. faecalis CECT 5728-fermented milk with significant ACEinhibitory activity and a similar E. faecalis CECT 5728-fermented milk with a high Ca content. Different parameters of these products (ACE-inhibitory activity, proteolysis degree reflecting functional peptide content, $\mathrm{Ca}$ content) were controlled and determined throughout the experimental period. To facilitate the interpretation of our results, we also measured the animals' weight gain and consumption of solid freely accessible feed and drinking fluid.

\section{Methods}

\section{Fermented milks}

The strain used in the present study to produce fermented milk with ACE-inhibitory activity was E. faecalis CECT 5728, which belongs to the Grupo Leche Pascual S.A. culture collection. This micro-organism was maintained as stock culture in agar slants of M17 (Biokar Diagnostics, Beauvois, France), stored at $4^{\circ} \mathrm{C}$ in aerobic conditions and sub-cultured periodically.

Pre-cultures of E. faecalis CECT 5728 were prepared from commercial homogenized ultra heat-treated skimmed milk fortified with two commercial milk protein concentrates: $1.8 \%(w / w)$ Belka DL 403 (Bel Industries, Paris, France) and 1.8\% (w/w) MTM E70 (Meggle, Wasserburg, Germany). The mix was heated to $95^{\circ} \mathrm{C}$ for $15 \mathrm{~min}$, cooled to $42^{\circ} \mathrm{C}$ and inoculated with a loop of the stock culture to yield an initial bacterial concentration of $10^{5}-10^{7}$ colony-forming units per ml. Incubation was performed at $42^{\circ} \mathrm{C}$ overnight. This pre-culture was used to inoculate a milk formulation base to obtain a stock of fermented milk with high ACE-inhibitory activity. This stock was prepared with sweetened milk (10\% sugar) standardized to a fat level of $1.5 \%$ and supplemented with $1.8 \%$ (w/ w) MTM E70. It was pasteurized to $95^{\circ} \mathrm{C}$ for $15 \mathrm{~min}$, quickly cooled to $4^{\circ} \mathrm{C}$ and stored before use. For inoculation, this milk base was warmed to $42^{\circ} \mathrm{C}$ and the pre-culture was added to a final dose of $3 \%(\mathrm{w} / \mathrm{w})$. Fermentation was carried out during $24 \mathrm{~h}$ at $42^{\circ} \mathrm{C}$. The process was stopped by pasteurization of the fermented milk at $75^{\circ} \mathrm{C}$ for $1 \mathrm{~min}$. Then it was cooled to $4^{\circ} \mathrm{C}$ and stored until being used to prepare the fermented milks used in the experimental trial. Aliquots of the stock were taken to measure its ACE-inhibitory activity.

For the experimental groups that were to be treated with E. faecalis CECT 5728-fermented milk in the present study, the fermented milk was always prepared from stock fermented milk normalized to an ACE-inhibitory activity of about $3000 \mathrm{IU} / \mathrm{ml}$. We attained this ACE-inhibitory activity by blending the stock with variable quantities of a sweetened aromatized commercial yoghurt drink (Yosport $^{\circledR}$; Grupo Leche Pascual, Aranda de Duero, Spain) depending on the initial ACE-inhibitory activity of the stock. In one of these experimental groups, the standardized fermented milk was enriched with $\mathrm{Ca}(\approx 2 \mathrm{~g} / \mathrm{l})$. Only sweetened aromatized commercial yoghurt drink was used to prepare the fermented milk assigned for the negative control group in this study. Finally, all the fermented milk mixes were pasteurized at $75^{\circ} \mathrm{C}$ for $1 \mathrm{~min}$, rapidly cooled to $4^{\circ} \mathrm{C}$ and kept until use.

The $o$-phthaldialdehyde method was used to measure proteolysis in the fermented milks (Church et al. 1983). A standard calibration curve was prepared with increasing concentrations of casein peptone hydrolysate. Results were expressed as $\mathrm{mg}$ casein peptone hydrolysate per $\mathrm{ml}$ sample. Unfermented milk was used as blank and subtracted from the value for each sample.

In order to measure the ACE-inhibitory activity, aliquots of fermented milks were pasteurized, vigorously stirred and centrifuged at $20000 \mathrm{~g}$ for $10 \mathrm{~min}$ to obtain the whey fraction. The collected supernatants were filtered through a Whatman no. 40 filter, analysed by semi-preparative reverse-phase HPLC and used to determine the ACE-inhibitory activity by spectrophotometric assay according to the method of Cushman \& Cheung (1971). The ACE-inhibitory activity was expressed as inhibition units according to the definition given by Nakamura et al. (1995b).

A standard HPLC method for quantifying inorganic cations was used to determine the $\mathrm{Ca}$ content in the whey fraction of the fermented milks. The chromatographic system (Hewlett-Packard Co., Palo Alto, CA, USA) consisted of a Hewlett-Packard 1050 pump, a Metrohm 690 UV-visible detector of ionic conductivity (Metrohm Ltd, Herisau, Switzerland) and a Waters 717 plus injector (Waters, Milford, MA, USA). Samples were warmed to $60^{\circ} \mathrm{C}$ under continuous stirring and cooled to room temperature. Aliquots $(5 \mathrm{ml})$ were transferred to porcelain dishes, dried at $90^{\circ} \mathrm{C}$ overnight and incinerated at $550^{\circ} \mathrm{C}$ for $90 \mathrm{~min}$. Ashes were dissolved in aqueous nitric acid solution $(25 \%)$ and the solvent evaporated at $100^{\circ} \mathrm{C}$ before incineration at $550^{\circ} \mathrm{C}$ for $90 \mathrm{~min}$. Then, the pellets were re-dissolved in the same nitric acid solution, and the solution filtered through a Whatman no. 40 filter and diluted 1:1000 (v/v) with distilled water. Diluted samples were filtered through a $0.45 \mu \mathrm{m}$ syringe filter. Finally, the processed samples were analysed in an HPLC column (Metrohm Ltd) of $150 \mathrm{~mm} \times 4.0 \mathrm{~mm}$, with a $7 \mu \mathrm{m}$ particle stationary phase. The chromatographic conditions were as follows: column temperature, $25^{\circ} \mathrm{C}$; flow, $1.0 \mathrm{ml} / \mathrm{min}$; injection volume, $20 \mu \mathrm{l}$; mobile phase, $4 \mathrm{mmol}$ tartaric acid/l and $1 \mathrm{mmol}$ 2,6-pyridinedicarboxylic acid/l.

Table 1 shows the exact characteristics and nutritional details of the different fermented milks used in this study.

\section{Experimental procedure in rats}

After being weaned at 3 weeks, male SHR (Charles River Laboratories España S.A., Barcelona, Spain) were caged in groups of five at a temperature of $23^{\circ} \mathrm{C}$ with $12 \mathrm{~h}$ light $/ 12 \mathrm{~h}$ dark cycles. They were in turn randomized with ad libitum intake into five groups of animals. Until they were 20 weeks old, the rats in these groups received drinking fluid as follows: tap water (negative control 1), a fermented milk without ACE-inhibitory activity (negative control 2), captopril (positive control, $100 \mathrm{mg} / \mathrm{kg}$; Sigma, St. Louis, MO, USA), E. faecalis CECT 5728-fermented milk that had significant ACE-inhibitory activity (about $3000 \mathrm{UI} / \mathrm{ml}$ ), or Ca-enriched E. faecalis CECT 5728-fermented milk that also had about 3000 UI ACE-inhibitory activity per ml. Thereafter, from the 20th to 25th week of life, animals in the different groups received tap water as drinking fluid. During the experimental period, the SHR of the five established groups were fed on a solid standard diet for rats (A04; Panlab, Barcelona, Spain).

SBP and DBP were measured weekly in the rats, from the 6th to 25th week of life, by the tail-cuff method (Buñag, 1973). Before measurement, the rats were kept at $37^{\circ} \mathrm{C}$ for $10 \mathrm{~min}$ to make the pulsations of the tail artery detectable. The original technique for measuring arterial blood pressure using the tailcuff method provides only SBP values, but the equipment used in the present study, LE 5001 (Letica, Hospitalet, Barcelona, 
Table 1. Characteristics of the different fermented milks

(Mean values and their standard error for a minimum of six determinations)

\begin{tabular}{|c|c|c|c|c|c|c|}
\hline & \multicolumn{2}{|c|}{ Negative control } & \multicolumn{2}{|c|}{ CECT 5728} & \multicolumn{2}{|c|}{ Ca-CECT 5728} \\
\hline & Mean & SEM & Mean & SEM & Mean & SEM \\
\hline Energy (kJ/100 ml) & $335 \cdot 1$ & 0.08 & $335 \cdot 1$ & 0.08 & $335 \cdot 1$ & 0.08 \\
\hline Protein $(\mathrm{g} / 100 \mathrm{ml})$ & $3 \cdot 75$ & 0.02 & 3.75 & 0.02 & $3 \cdot 75$ & 0.02 \\
\hline Fat $(\mathrm{g} / 100 \mathrm{ml})$ & 1.35 & 0.02 & 1.35 & 0.02 & 1.35 & 0.02 \\
\hline Carbohydrate (g/100 ml) & $13 \cdot 14$ & 0.02 & $13 \cdot 14$ & 0.02 & $13 \cdot 14$ & 0.02 \\
\hline ACE-inhibitory activity (IU/ml) & 153 & 53 & $2951^{a}$ & 364 & $2951^{\mathrm{a}}$ & 364 \\
\hline Proteolysis degree (mg peptide/ml) & 0.74 & 0.06 & $1 \cdot 82^{\mathrm{a}}$ & 0.10 & $1 \cdot 82^{\mathrm{a}}$ & 0.10 \\
\hline Calcium content $(\mathrm{g} / \mathrm{l})$ & 1.57 & 0.02 & 1.57 & 0.02 & $2 \cdot 03^{a, b}$ & 0.02 \\
\hline
\end{tabular}

Negative control, milk fermented by Lactobacillus delbrueckii and Streptococcus thermophilus without ACE-inhibitory activity; CECT 5728, Enterococcus faecalis CECT 572-fermented milk; Ca-CECT 5728, Ca-enriched E. faecalis CECT 5728 fermented-milk; ACE, angiotensin-converting enzyme

${ }^{\mathrm{a}} P<0.05$ v. negative control; ${ }^{\mathrm{b}} P<0.05$ v. CECT 5728 .

Spain), has a high-sensitivity pulse transducer coupled with an accurate microprocessor program, and allows us to distinguish between SBP and DBP. The arterial blood pressure measurements were performed at the same time of day (between 09.00 and 13.00 hours) in order to avoid any influence of the circadian cycle. Moreover, the researchers who measured the arterial blood pressure in the animals of the different groups did not know the exact drinking fluid that had been administered to each of these groups.

We took weekly measurements of rat weight up to the 25 th week of life in the different groups. The consumption of drinking fluids and freely accessible feed was also estimated weekly in the animals of the different groups throughout the experimental period.

All of the experiments were performed as authorized for scientific research (European Directive 86/609/CEE and Royal Decree 223/1988 of the Spanish Ministry of Agriculture, Fisheries and Food).

\section{Statistical analysis}

The results are expressed as means with their standard error for a minimum of eight rats and were analysed by one-way ANOVA. Differences between the groups were assessed by the Bonferroni test. We considered the differences between the means to be significant when $P<0 \cdot 05$.

\section{Results}

The SHR of the negative control groups showed a gradual increase in SBP and DBP from weaning that reached maximal values at 11 weeks of life. From this age the arterial blood pressure of the rats remained constantly high and their SBP and DBP values were similar between weeks 11 and 25 . These variables were slightly lower in the SHR of the negative control 2 group that drank the fermented milk without ACE-inhibitory activity than in the SHR of the negative control 1 group that drank tap water. A definite decrease in SBP and DBP could be observed in the rats of the positive control group treated with captopril from the 6th to the 20th week of life. In these animals, both SBP and DBP values remained constant during this period. The E. faecalis CECT 5728-fermented milks also decreased SBP and DBP in the SHR. The antihypertensive effect of these products was less accentuated than the effect of the pharmacological treatment, but could be clearly appreciated from the 13th to the 20th week of life. The effect of the Ca-enriched fermented milk was more accentuated than the effect of the E. faecalis CECT 5728fermented milk that had not been enriched in Ca. An increase in SBP and DBP was observed in the SHR that had been treated with the E. faecalis CECT 5728-fermented milks when these rats were given tap water as drinking fluid at the 20th week of life. SBP and DBP were in fact similar in these SHR and in the SHR of the negative control groups when the animals were 25 weeks old. SBP and DBP also increased somewhat in the SHR that had received captopril when we took away the pharmacological treatment. However, despite this, these variables were lower in the 20- to 25-week-old SHR that received the drug than in the SHR of the same age in the other groups (see Figs 1 and 2). Considering the results presented earlier, we believe that comparisons of the SBP and DBP values in the 11-, 20- and 25-week-old SHR of the different groups permit us to establish the effect of the products administered in the animals. Table 2 shows these values and these comparisons.

The body weight of the SHR increased progressively in all groups. The increase was less accentuated in the SHR of the positive control 1 group treated with captopril than in the other groups. On the contrary, the rats treated with the fermented milks exhibited a significantly increased weight gain compared with the animals that drank tap water. The increase was less accentuated in the SHR treated with the Ca-enriched E. faecalis CECT 5728-fermented milk, and these animals showed slightly lower body weight values than the SHR of the groups treated with the other fermented milks (see Fig. 3). The comparisons of the body weight values in the 11-, 20- and 25-week-old SHR of the different groups are shown in Table 2.

Between the 5th and 20th weeks of life, we observed a considerable dry food intake and a scarce liquid food consumption in the SHR of the negative control 1 group and in the group treated with captopril. By contrast, dry food intake decreased and liquid diet consumption increased in the SHR that drank the different fermented milks during this period. The increase in liquid consumption was more noticeable in the SHR treated with the fermented milk without ACE-inhibitory activity. From the 20th to the 25th week of life, the consumption of solid food and drinking fluid was very similar in all groups. It should be remembered that during this period all of the animals drank tap water as had the animals included in the negative control 1 group from the beginning of the experiment (see Figs 4 and 5). 


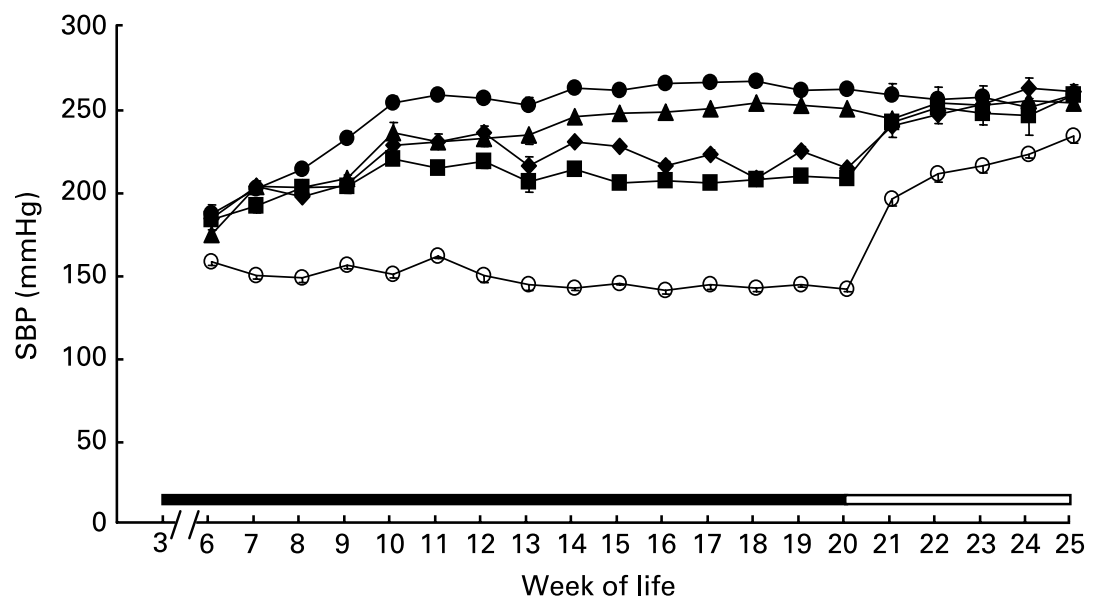

Fig. 1. Systolic blood pressure (SBP) of spontaneously hypertensive rats. The animals drank different fluids from weaning until the 20th week of life (treatment period indicated by a solid bar): tap water $(\bullet)$, fermented milk without angiotensin-converting enzyme (ACE)-inhibitory activity $(\mathbf{\Lambda})$, captopril $100 \mathrm{mg} / \mathrm{kg}(\bigcirc)$, Enterococcus faecalis CECT 5728-fermented milk with significant ACE-inhibitory activity $(\bullet)$, or Ca-enriched E. faecalis CECT 5728 -fermented milk with significant ACE-inhibitory activity (ם). All rats drank tap water from the 20th until the 25th week of life (follow-up period indicated by an open bar). Values are means with their standard error shown by vertical bars for a minimum of eight rats.

Comparisons of the values of dry food intake and liquid food consumption in the 11-, 20- and 25-week-old SHR of the different groups are also shown in Table 2 .

\section{Discussion}

Before starting the present study, we knew that milk fermented by E. faecalis, and some peptides with in vitro ACE-inhibitory activity isolated from this milk, decreased arterial blood pressure in SHR when acutely administered by intragastric intubation. Hypertension is a chronic pathology that requires chronic treatment, and the long-term administration of functional products without side-effects is an attractive possibility to be considered in treating this pathology. For these reasons, we believed it advisable to carry out the present study in which we investigated the changes in arterial blood pressure in SHR caused by long-term oral intake of a milk fermented by one E. faecalis strain (E. faecalis CECT 5728) characterized as a producer of ACEinhibitory peptides. Since we had also demonstrated with previous studies that Ca-enriched diets could control hypertension in SHR (Civantos \& Aleixandre, 2004), we also believed it interesting to evaluate the effect on blood pressure of long-term oral intake of a Ca-enriched E. faecalis CECT 5728-fermented milk in these animals.

As can be seen in Figs 1 and 2, the SHR that drank tap water throughout the experimental period showed a gradual increase in SBP and DBP, which reached maximum values at about 11 weeks of life. The other groups of rats also showed an accentuated increase in arterial blood pressure from weaning until the 12th week of life, after which point arterial blood pressure reached stable levels in all groups. It was not surprising to observe lesser values of SBP and DBP during the experimental period

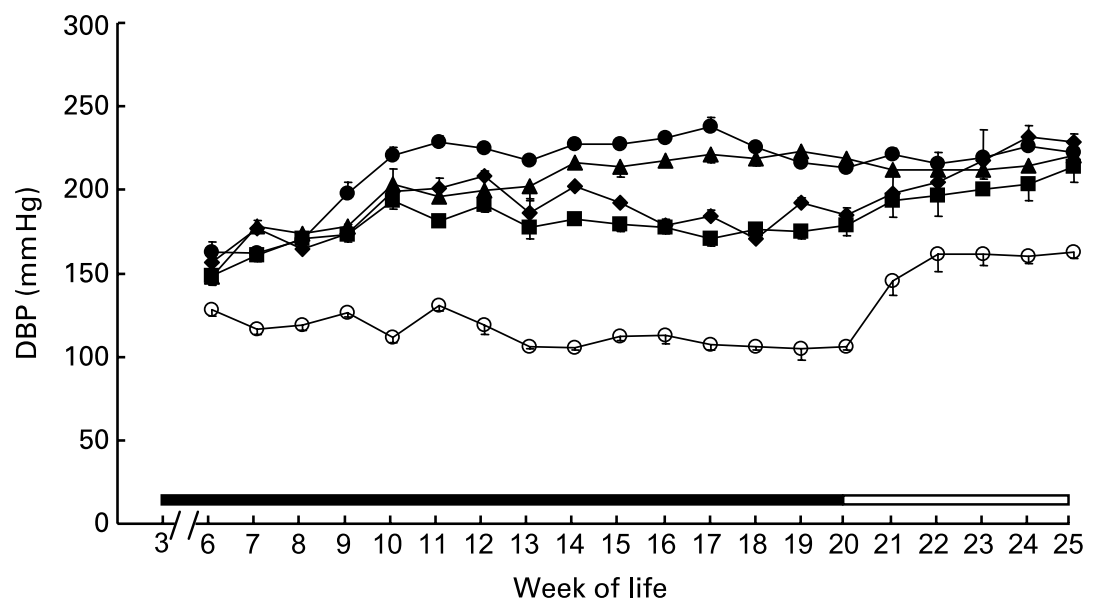

Fig. 2. Diastolic blood pressure (DBP) of spontaneously hypertensive rats. The animals drank different fluids from weaning until the 20th week of life (treatment period indicated by a solid bar): tap water $(\bullet)$, fermented milk without angiotensin-converting enzyme (ACE)-inhibitory activity $(\boldsymbol{\Lambda})$, captopril $100 \mathrm{mg} / \mathrm{kg}(\bigcirc)$, Enterococcus faecalis CECT 5728-fermented milk with significant ACE-inhibitory activity $(\diamond)$, or Ca-enriched E. faecalis CECT 5728 -fermented milk with significant ACE-inhibitory activity ( $\square$ ). All rats drank tap water from the 20th until the 25 th week of life (follow-up period indicated by an open bar). Values are means with their standard error shown by vertical bars for a minimum of eight rats. 
Table 2. Values of the studied variables in the 11-, 20- and 25-week-old spontaneously hypertensive rats of the different groups (Mean values and their standard error for a minimum of eight determinations)

\begin{tabular}{|c|c|c|c|c|c|c|c|c|c|c|}
\hline & \multicolumn{2}{|c|}{ Tap water } & \multicolumn{2}{|c|}{ Negative control } & \multicolumn{2}{|c|}{ Positive control } & \multicolumn{2}{|c|}{ CECT 5728} & \multicolumn{2}{|c|}{ Ca-CECT 5728} \\
\hline & Mean & SEM & Mean & SEM & Mean & SEM & Mean & SEM & Mean & SEM \\
\hline \multicolumn{11}{|l|}{11 weeks old } \\
\hline $\mathrm{SBP}(\mathrm{mmHg})$ & $258 \cdot 1$ & 3.03 & $229 \cdot 32^{\mathrm{a}}$ & $2 \cdot 30$ & $160 \cdot 70^{\mathrm{a}, \mathrm{b}}$ & 1.51 & $229 \cdot 66^{\mathrm{a}, \mathrm{c}}$ & 4.90 & $214 \cdot 01^{a, b, c, d}$ & $3 \cdot 25$ \\
\hline $\mathrm{DBP}(\mathrm{mmHg})$ & $228 \cdot 27$ & 3.72 & $196 \cdot 06^{\mathrm{a}}$ & 4.07 & $130 \cdot 53^{a, b}$ & $2 \cdot 86$ & $201 \cdot 00^{\mathrm{a}, \mathrm{c}}$ & $6 \cdot 19$ & $181 \cdot 07^{\mathrm{a}, \mathrm{c}, \mathrm{d}}$ & 3.25 \\
\hline Body weight (g) & $282 \cdot 3$ & 4.5 & $302 \cdot 3$ & $3 \cdot 8$ & $264.5^{\mathrm{b}}$ & $4 \cdot 7$ & $312 \cdot 5^{\mathrm{a}, \mathrm{c}}$ & $6 \cdot 5$ & $315 \cdot 0^{\mathrm{a}, \mathrm{c}}$ & $10 \cdot 1$ \\
\hline Liquid consumption (ml/d per rat) & $29 \cdot 02$ & $2 \cdot 70$ & $80 \cdot 71$ & $14 \cdot 14$ & 35.97 & 3.69 & $59 \cdot 54$ & 1.02 & $67 \cdot 28$ & $31 \cdot 13$ \\
\hline \multicolumn{11}{|l|}{20 weeks old } \\
\hline $\mathrm{SBP}(\mathrm{mmHg})$ & $261 \cdot 13$ & 2.69 & $250 \cdot 00$ & $2 \cdot 77$ & $140 \cdot 53^{a, b}$ & 1.52 & $213 \cdot 89^{a, b, c}$ & $2 \cdot 71$ & $207 \cdot 33^{a, b, c}$ & $2 \cdot 00$ \\
\hline $\mathrm{DBP}(\mathrm{mmHg})$ & $213 \cdot 13$ & 1.91 & $218 \cdot 50$ & $2 \cdot 14$ & $106 \cdot 06^{a, b}$ & $2 \cdot 17$ & $184 \cdot 83^{\mathrm{a}, \mathrm{b}, \mathrm{c}}$ & 4.03 & $178 \cdot 80^{\mathrm{a}, \mathrm{b}, \mathrm{c}}$ & 6.08 \\
\hline Body weight (g) & 353.5 & $5 \cdot 2$ & $377 \cdot 2$ & $6 \cdot 8$ & $326 \cdot 6^{\mathrm{b}}$ & 7.5 & $386 \cdot 5^{\mathrm{a}, \mathrm{c}}$ & $7 \cdot 4$ & $407 \cdot 0^{\mathrm{a}, \mathrm{c}}$ & $10 \cdot 5$ \\
\hline Liquid consumption (ml/d per rat) & 28.83 & 0.05 & $71 \cdot 21^{\mathrm{a}}$ & 1.84 & $39 \cdot 39^{b}$ & 0.30 & $58 \cdot 64^{\mathrm{a}}$ & 1.99 & $73 \cdot 67^{\mathrm{a}, \mathrm{c}}$ & 6.06 \\
\hline Solid consumption (g/d per rat) & $19 \cdot 46$ & 0.83 & $8 \cdot 11^{\mathrm{a}}$ & 0.09 & $18 \cdot 60^{\mathrm{b}}$ & 0.87 & $5 \cdot 98^{\mathrm{a}, \mathrm{c}}$ & $1 \cdot 23$ & $6 \cdot 59^{a, c}$ & $1 \cdot 21$ \\
\hline \multicolumn{11}{|l|}{25 weeks old } \\
\hline $\mathrm{SBP}(\mathrm{mmHg})$ & $258 \cdot 10$ & 5.00 & $253 \cdot 30$ & $4 \cdot 17$ & $233 \cdot 14^{\mathrm{a}}$ & $4 \cdot 33$ & $260 \cdot 00^{\mathrm{C}}$ & 4.04 & $257.94^{\mathrm{C}}$ & 1.49 \\
\hline Body weight $(\mathrm{g})$ & $366 \cdot 4$ & $4 \cdot 4$ & $389 \cdot 3$ & $12 \cdot 3$ & $350 \cdot 8$ & $14 \cdot 8$ & $378 \cdot 2$ & $16 \cdot 4$ & $366 \cdot 1$ & $6 \cdot 7$ \\
\hline Liquid consumption (ml/d per rat) & $36 \cdot 28$ & $2 \cdot 29$ & 33.93 & $2 \cdot 21$ & 31.07 & 3.50 & 37.98 & $8 \cdot 35$ & 45.95 & $2 \cdot 21$ \\
\hline Solid consumption ( $\mathrm{g} / \mathrm{d}$ per rat) & $20 \cdot 37$ & 0.78 & $20 \cdot 45$ & 0.94 & $19 \cdot 57$ & 0.13 & $20 \cdot 82$ & 0.17 & $20 \cdot 58$ & 0.07 \\
\hline
\end{tabular}

Negative control, fermented milk without angiotensin-converting enzyme (ACE)-inhibitory activity; positive control, captopril (100 mg/kg); CECT 5728, Enterococcus faecalis CECT 5728fermented milk; Ca-CECT 5728, Ca-enriched E. faecalis CECT 5728-fermented milk; SBP, systolic blood pressure; DBP, diastolic blood pressure.

${ }^{\mathrm{a}} P<0.05 \mathrm{v}$. tap water; ${ }^{\mathrm{b}} P<0.05 \mathrm{v}$. negative control; ${ }^{\mathrm{c}} P<0.05 \mathrm{v}$. positive control; ${ }^{\mathrm{d}} P<0.05 \mathrm{v}$. CECT 5728.

in the group of SHR that were treated with captopril, because this drug is a prototype ACE inhibitor with clinical use in hypertensive patients. The groups of SHR treated with the E. faecalis CECT 5728-fermented milk, and with the Ca-enriched E. faecalis CECT 5728-fermented milk, also showed a clear decrease in arterial blood pressure that was probably related to the antihypertensive peptides produced when milk is fermented by this bacterium. The data obtained when we evaluated the ACE-inhibitory activity and the proteolysis degree of these milks (shown in Table 1) clearly guarantee that biologically active peptide fragments are implicated in their effects on arterial blood pressure. In fact, our research group has already isolated some peptides from the E. faecalis CECT 5728-fermented milk (mainly the peptidic sequence Leu-His-Leu-Pro-Leu-Pro) that are ACE inhibitors and have an acute antihypertensive effect in SHR. These data have been included in a patent presented by Muguerza et al. (2003).

As mentioned earlier, Sipola et al. (2001) demonstrated that long-term oral administration of IPP and VPP, two tripeptides isolated by Nakamura et al. (1995a) from a milk fermented by L. helveticus and S. cerevisiae, and also the chronic intake of a sour milk containing these tripeptides, attenuated the development of hypertension in young SHR. As in the present study, Sipola et al. measured the SBP of the SHR by the tail-cuff method

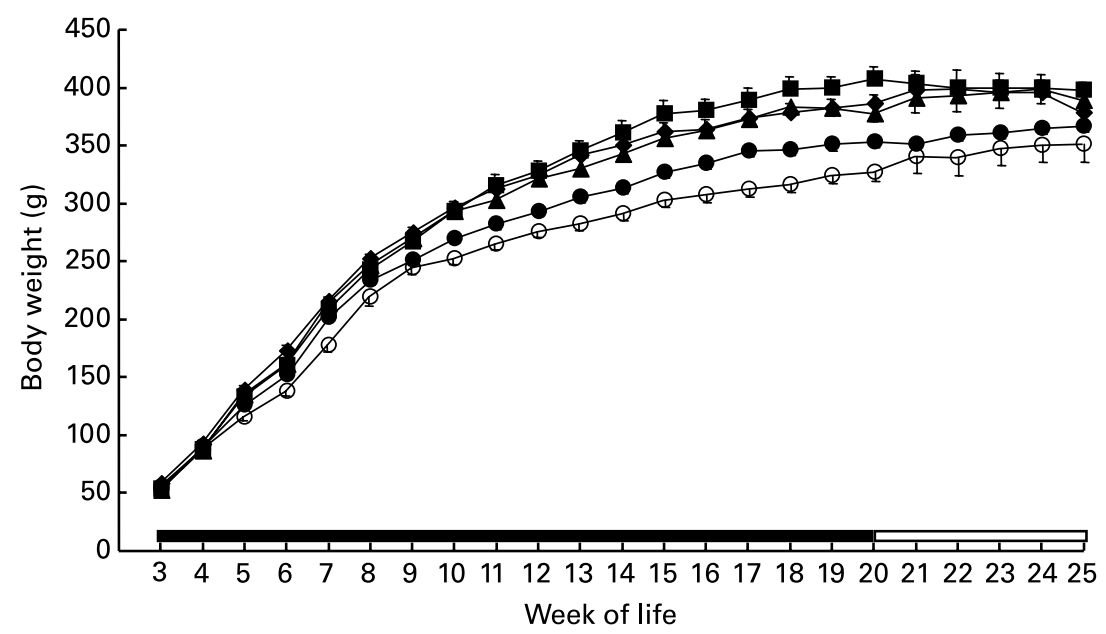

Fig. 3. Body weight of spontaneously hypertensive rats. The animals drank different fluids from weaning until the 20th week of life (treatment period indicated by a solid bar): tap water $(\bullet)$, fermented milk without angiotensin-converting enzyme (ACE)-inhibitory activity $(\mathbf{\Delta})$, captopril $100 \mathrm{mg} / \mathrm{kg}(O)$, Enterococcus faecalis CECT 5728-fermented milk with significant ACE-inhibitory activity $(\$)$, or Ca-enriched E. faecalis CECT 5728-fermented milk with significant ACE-inhibitory activity ( $\square$ ). All rats drank tap water from the 20th until the 25th week of life (follow-up period indicated by an open bar). Values are means with their standard error shown by vertical bars for a minimum of eight rats. 


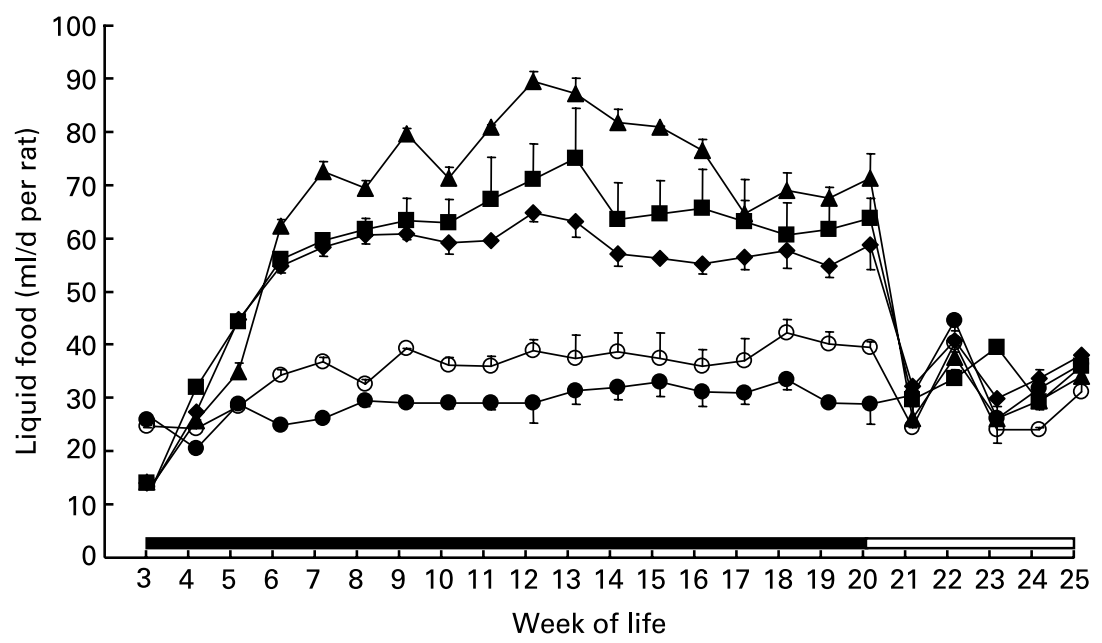

Fig. 4. Liquid food consumption of spontaneously hypertensive rats. The animals drank different fluids from weaning until the 20th week of life (treatment period indicated by a solid bar): tap water $(\bullet)$, fermented milk without angiotensin-converting enzyme (ACE)-inhibitory activity (ム), captopril $100 \mathrm{mg} / \mathrm{kg}(\bigcirc)$, Enterococcus faecalis CECT 5728-fermented milk with significant ACE-inhibitory activity ( $\bullet$ ), or Ca-enriched E. faecalis CECT 5728-fermented milk with significant ACEinhibitory activity $(\square)$. All rats drank tap water from the 20th until the 25th week of life (follow-up period indicated by an open bar). Values are means with their standard error shown by vertical bars for a minimum of eight rats.

from the 6th week of life, but they did not report data on the DBP of these animals. These researchers concluded that one possible mechanism underlying the antihypertensive effect of the sour milk containing VPP and IPP was the ACE-inhibitory activity of these sequences. Most of the peptide fragments with ACEinhibitory activity that have been isolated from hydrolysates of food materials, among them the peptidic sequences VPP and IPP, and also the sequence Leu-His-Leu-Pro-Leu-Pro isolated from the E. faecalis CECT 5728-fermented milk, have a proline group in the carboxyl terminus.

In the present study we have also shown that SBP and DBP were slightly lower in the SHR that drank the fermented milk without ACE-inhibitory activity (milk fermented by Lactobacillus delbrueckii and Streptococcus thermophilus) than in the SHR that drank tap water. Ashar \& Chand (2004) very recently demonstrated that $L$. delbrueckii also has proteolytic ability to generate ACE-inhibitory peptides during milk fermentation, but the antihypertensive effect of these peptides has still not been demonstrated. Thus, we cannot discard that some functional antihypertensive peptides may also be produced in the fermentation process when bacteria different from E. faecalis ferment the milk. In addition, as can be seen in Figs 1 and 2, in the group of rats treated with the Ca-enriched milk the antihypertensive effect was particularly constant, and the development of hypertension was somewhat more extensively attenuated than in the group of rats treated with the E. faecalis CECT 5728-fermented milk not enriched in $\mathrm{Ca}$. The increase in $\mathrm{Ca}$ content seems therefore to improve the antihypertensive properties of the E. faecalis CECT 5728fermented milk. Sipola et al. (2001) also concluded that the

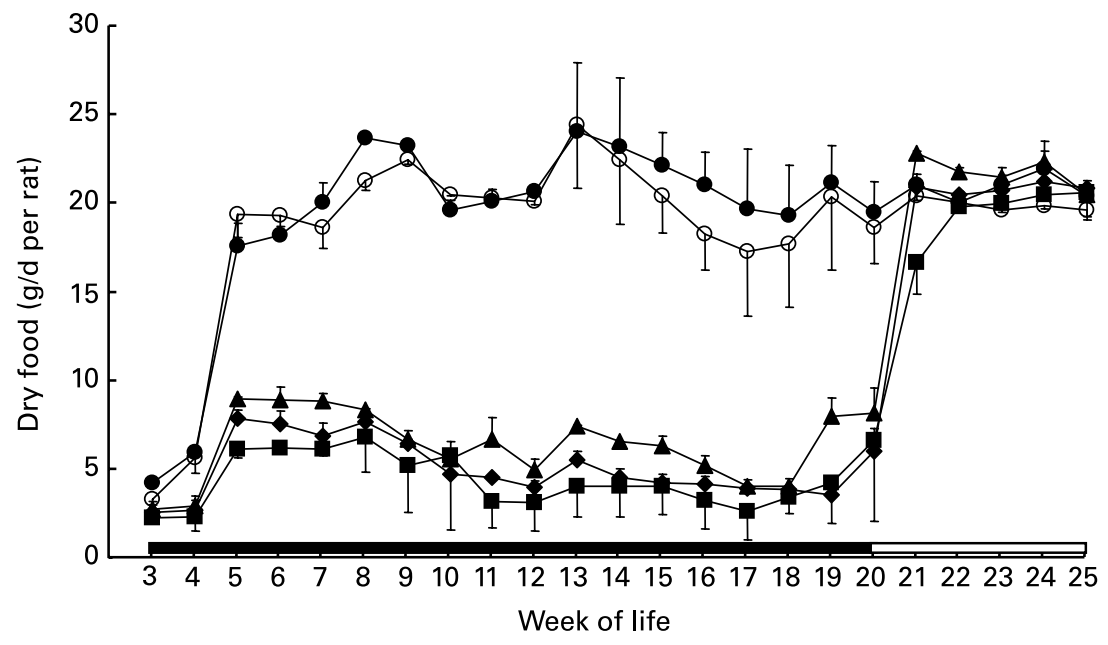

Fig. 5. Dry food intake of spontaneously hypertensive rats. The animals drank different fluids from weaning until the 20th week of life (treatment period indicated by a solid bar): tap water $(\bullet)$, fermented milk without angiotensin-converting enzyme (ACE)-inhibitory activity $(\mathbf{\Lambda})$, captopril $100 \mathrm{mg} / \mathrm{kg}(\bigcirc)$, Enterococcus faecalis CECT 5728-fermented milk with significant ACE-inhibitory activity $(\bullet)$, or Ca-enriched E. faecalis CECT 5728-fermented milk with significant ACE-inhibitory activity (匚). All rats drank tap water from the 20th until the 25 th week of life (follow-up period indicated by an open bar). Values are means with their standard error shown by vertical bars for a minimum of eight rats. 
role of $\mathrm{Ca}$ in the antihypertensive effect of the milk fermented by $L$. helveticus and $S$. cerevisiae cannot be ruled out.

After withdrawal of the treatments, SBP and DBP in the animals that had drunk the E. faecalis CECT 5728-fermented milks rose gradually, and approximately 2 weeks later these variables reached similar levels to those obtained in the control groups. This also demonstrates that functional antihypertensive peptides are present in these products. Sipola et al. (2001) also described a gradual rise in the SBP of SHR after withdrawal of the treatments used in their study (the fermented milk containing VPP and IPP and the treatment with these two tripeptides). In the present study, it was also logical to observe an increase in arterial blood pressure of the rats that had been treated with captopril after the withdrawal of this treatment. Since this drug is a potent ACE inhibitor, the reversion of its effect was, nevertheless, less noticeable than the reversion of the effect of the E. faecalis CECT 5728fermented milks.

We have also studied the influence of the different treatments on weight gain and food consumption of the SHR, and it is evident that the nutritional value of the fermented milks consumed by the rats was adequate as they improved animal growth (Fig. 3). This effect is independent of the ACE-inhibitory activity because, on the one hand, the group of rats treated with captopril had similar body weight gain to those that drank tap water and, on the other, the increase in body weight was also clear in the group of SHR that drank the milk fermented by bacteria other than E. faecalis. Moreover, since liquid consumption increased in the groups of SHR that were drinking the fermented milks, we can assume that these products are pleasant to ingest. The increase in liquid consumption is logically accompanied by a decrease in dry food consumption; Fig. 4 shows this decrease in the groups of SHR that drank the fermented milks.

The experimental model of SHR has usually been used to carry out initial studies to evaluate the antihypertensive effect of functional products and bioactive peptides derived from food proteins (Karaki et al. 1990; Saito et al. 1994; Yamamoto et al. 1994, 1999; Kuwabara et al. 1995; Fujita \& Yoshikawa, 1999; Nurminen et al. 2000; Shin et al. 2001; Sipola et al. 2001; Wu \& Ding, 2001). The results that we have obtained in this rat strain with the E. faecalis CECT 5728-fermented milk suggest the possibility of using this milk in the non-pharmacological treatment of hypertension. In fact, all of the mentioned data demonstrate that milk fermentation with E. faecalis CECT 5728 may be a successful strategy to produce a functional food with antihypertensive activity. Nevertheless, we have to bear in mind that some differences exist in bowel structure and function, and also in microflora, between rodents and man. It is therefore evident that before using the milk fermented by E. faecalis CECT 5728 in human subjects, it would be necessary to carry out clinical studies to demonstrate their efficiency and to guarantee their safe use in hypertensive patients. The present results also suggest that the increase in $\mathrm{Ca}$ content may improve the antihypertensive properties of the E. faecalis CECT 5728-fermented milk. This should also be considered in the future to elaborate a functional food with the E. faecalis CECT 5728-fermented milk.

\section{Acknowledgements}

This study was supported by Leche Pascual S.A. and by an INIAMCYT project (CAL01-046-02). We thank Ignacio Villar and
Daniel Reñé for the technical assistance in the production of the fermented milks. We also thank Manuel Bas Caro, Technician in Pharmacology, for the excellent care of the rats and control of the diets in the different groups of animals.

\section{References}

Aleixandre MA \& Puerro M (1993) Importancia del calcio en la dieta para la regulación de la presión arterial. Med Clin (Barc) 101, 660-667.

Aleixandre MA, Puerro M \& Lizasoain I (1993) Mecanismos alternativos del efecto hipotensor del calcio. Hipertensión 10, 96-102.

Allender PS, Cutler JA, Follmann D, Cappuccio FP, Pryer J \& Elliot P (1996) Dietary calcium and blood pressure: a meta-analysis of randomized clinical trials. Ann Intern Med 124, 825-831.

Ashar MN \& Chand R (2004) Antihypertensive peptides purified from milks fermented with Lactobacillus delbrueckii ssp. bulgaricus. Milchwissenschaft 59, 14-17.

Buñag RD (1973) Validation in awake rats of a tail-cuff method for measuring systolic pressure. J Appl Physiol 34, 279-282.

Church FC, Swaisgood HE, Porter DH \& Catignani GL (1983) Spectrophotometric assay using $o$-phthaldialdehyde for determination on proteolysis in milk and isolated milk proteins. J Dairy Sci 66, 1219-1227.

Civantos B \& Aleixandre A (2004) Changes in arterial blood pressure and $\alpha$ vascular reactivity caused in spontaneously hypertensive rats by a long-term combined treatment with amlodipine and dietary calcium supplements. Eur J Pharmacol 489, 101-110.

Civantos B, López-Miranda V, Ortega A \& Aleixandre MA (1999) Alphaadrenoceptor-mediated pressor responses in pithed rats fed on diets with a different calcium content. Eur J Pharmacol 382, 91-101.

Civantos Calzada B \& Aleixandre de Artiñano A (2003) Effects of dietary calcium supplements and amlodipine on growth, arterial blood pressure, and cardiac hypertrophy of spontaneously hypertensive rats. Clin Exp Hypertens 25, 495-508.

Cushman DW \& Cheung HS (1971) Spectrophotometric assay and properties of the angiotensin-converting enzyme of rabbit lung. Biochem Pharmacol 20, 1637-1648.

Fujita H \& Yoshikawa M (1999) LKPNM: a prodrug-type ACE-inhibitory peptide derived from fish protein. Immunopharmacology 44, 123-127.

Hata Y, Yamamoto M, Ohni M, Nakajima K, Nakamura Y \& Tacano T (1996) A placebo-controlled study of the effect of sour milk on blood pressure in hypertensive subjects. Am J Clin Nutr 64, 767-771.

Karaki H, Doi K, Sugano S, Uchiwa H, Sugai R, Murakami U \& Takemoto S (1990) Antihypertensive effect of tryptic hydrolysate of milk casein in spontaneously hypertensive rats. Comp Biochem Physiol 96, 367-371.

Kuwabara Y, Nagai S, Yoshimitsu N, Nakagawa I, Watanabe Y \& Tamai Y (1995) Antihypertensive effect of the milk fermented by culturing with various lactic acid bacteria and a yeast. J Ferment Bioeng 80, 294-295.

López-Miranda V, Civantos B, Blasco R, Fernández R \& Aleixandre A (1998) Parathyroid hormone and calcitriol in the hypertension caused by dietary calcium deficiency in rats. J Vasc Res 35, 397-404.

Muguerza B, Delgado MA, Quirós del Bosque A, Recio I, Ramos M \& Aleixandre A (2003) Cepas de Enterococcus faecalis productoras de péptidos, péptidos bioactivos y sus aplicaciones. ES Patent 200301186. International Patent PCT/ES2004/000227.

Muguerza B, Ramos M, Sánchez E, Manso MA, Miguel M, Aleixandre A, Delgado MA \& Recio I (2005) Antihypertensive activity of fermented milk by Enterococcus faecalis strains isolated from raw milk. Int Dairy J, (In the Press).

Nakamura Y, Yamamoto N, Sakai K \& Tacano T (1995a) Antihypertensive effect of sour milk and peptides isolated from it that are inhibitors to angiotensin I-converting enzyme. J Dairy Sci 78, 1253-1257.

Nakamura Y, Yamamoto N, Sakai K, Takano T, Okubo A \& Yamazaki S (1995b) Purification and characterization of angiotensin-I-converting enzyme from sour milk. J Dairy Sci 78, 777-783. 
Nurminen ML, Sipola M, Kaarto H, Pihlanto-Leppälä A, Piilola K, Korpela R, Tossavainen H, Korhonen H \& Vapaatalo H (2000) $\alpha$-Lactorphin lowers blood pressure measured by radiotelemetry in normotensive and spontaneously hypertensive rats. Life Sci 16, $1535-1543$.

Pryer J, Cappucio FP \& Elliot P (1995) Dietary calcium and blood pressure, a review of the observational studies. J Hum Hypertens 9, 597-604.

Resnick LM (1999) The role of dietary calcium in hypertension: a hierarchical overview. Am J Hypertens 12, 99-112.

Saito Y, Wanezaki K, Kawato A \& Imayasu S (1994) Antihypertensive effects of peptide in sake and its by-products on spontaneously hypertensive rats. Biosci Biotechnol Biochem 58, 812-816.

Seppo L, Kerojoki O, Suomalainen T \& Korpela R (2002) The effect of a Lactobacillus helveticus LBK-16 H fermented milk on hypertension: a pilot study on humans. Milchwissenschaft 57, 124-127.

Seppo L, Jauhiainen T, Poussa T \& Korpela R (2003) A fermented milk high in bioactive peptides has a blood pressure-lowering effect in hypertensive subjects. Am J Clin Nutr 77, 326-330.

Shin Z, Yu R, Park S, Chung D, Ahn C, Nam H, Kim K \& Lee H (2002) His-His-Leu, an angiotensin I converting enzyme inhibitory peptide derived from Korean soybean paste, exerts antihypertensive activity in vivo. J Agric Food Chem 49, 3004-3009.

Sipola M, Finckenberg P, Santisteban J, Korpela R, Vapaatalo H \& Nurminen M-L (2001) Long-term intake of milk peptides attenuates development of hypertension in spontaneously hypertensive rats. J Physiol Pharmacol 52, 745-754.

Sipola M, Finckenberg P, Korpela R, Vapaatalo H \& Nurminen M-L (2002) Effect of long-term intake of milk products on blood pressure in hypertensive rats. J Dairy Res 69, 103-111.

Wu J \& Ding X (2001) Hypotensive and physiological effect of angiotensin converting enzyme inhibitory peptides derived from soy protein on spontaneously hypertensive rats. J Agric Food Chem 49, 501-506.

Yamamoto N, Akino A \& Takano T (1994) Antihypertensive effect of the peptides derived from casein by an extracellular proteinase from Lactobacillus helveticus CP790. J Dairy Sci 77, 917-922.

Yamamoto N, Maeno M \& Takano T (1999) Purification and characterization of an antihypertensive peptide from a yogurt-like product fermented by Lactobacillus helveticus CPN4. J Dairy Sci 82 $1388-1393$. 